\title{
Respiration in marine pelagic copepods: a global-bathymetric model
}

\author{
Tsutomu Ikeda*, Fumikazu Sano, Atsushi Yamaguchi
}

Plankton Laboratory, Graduate School of Fisheries Sciences, Hokkaido University, Minato-cho, Hakodate 041-8611, Japan

\begin{abstract}
Historical global respiration datasets of epipelagic copepods and recent bathymetric respiration datasets of mesopelagic, upper- and lower-bathypelagic and abyssopelagic copepods were combined to build a global-bathymetric respiration model by adopting 2 regression models (theoretical and empirical ones). Designated independent variables including body mass (expressed as dry mass, carbon or nitrogen), habitat temperature, ambient oxygen saturation and the depth of occurrence were all significant, accounting for 72 to $80 \%$ in the variation in these respiration data. Both theoretical and empirical regression models yielded similar results, but the latter was sensitive to the choice of body mass. The mechanisms leading to a negative effect of depth and a positive effect of oxygen saturation on respiration rates are thought to be due to 'predation-mediated selection' and the lack of specialized respiratory organs (i.e. oxygen diffusion through the body surface), respectively.
\end{abstract}

KEY WORDS: Respiration $\cdot$ Copepods $\cdot$ Global $\cdot$ Bathymetric $\cdot$ Model

\section{INTRODUCTION}

Copepods are the major component of marine mesozooplankton and may be the most numerous multicellular organisms on earth (Longhurst 1985, Mauchline 1998). In marine pelagic ecosystems, copepods are an important link between primary production and production of organisms at higher trophic levels. Because of their ubiquitous distribution, high abundance and trophic importance, vital rates of copepods and other mesozooplankton are of particular relevance for understanding oceanic biogeochemical cycles of carbon and other elements (Aristegui et al. 2005, HernandezLeon \& Ikeda 2005, Buitenhuis et al. 2006). Copepod respiration (= oxygen consumption) is a direct measure of mineralization and has been shown to be a function of body mass and habitat temperature for epipelagic copepods (Ivleva 1980, Ikeda et al. 2001); this principle has now been expanded to apply to all organisms on earth (Gillooly et al. 2001). While the ultimate importance of body mass and habitat temperature as determinants of copepod respiration (hereafter referred as the 'global' respiration model) was derived from statistical analyses of large datasets on epipelagic copepods collected from the world's oceans, its application to those living in the ocean's interior is currently inappropriate since a recent study indicated significantly lower respiration rates for copepods in the mesopelagic and bathypelagic zones of the ocean (Ikeda et al. 2006a). As a basis for advancing our understanding about the role of marine pelagic copepods in the entire ocean, the existing global respiration model needs to be modified to a global-bathymetric model by incorporating new datasets of deep-sea copepods.

\section{MATERIALS AND METHODS}

The 65 epipelagic respiration datasets were a compilation of rates measured at in situ temperatures over many years (1970-2004) using standardized methods (sealed-chamber method, cf. Ikeda et al. 2000) at various locations in the world's oceans (Fig. 1) (Ikeda et al. 


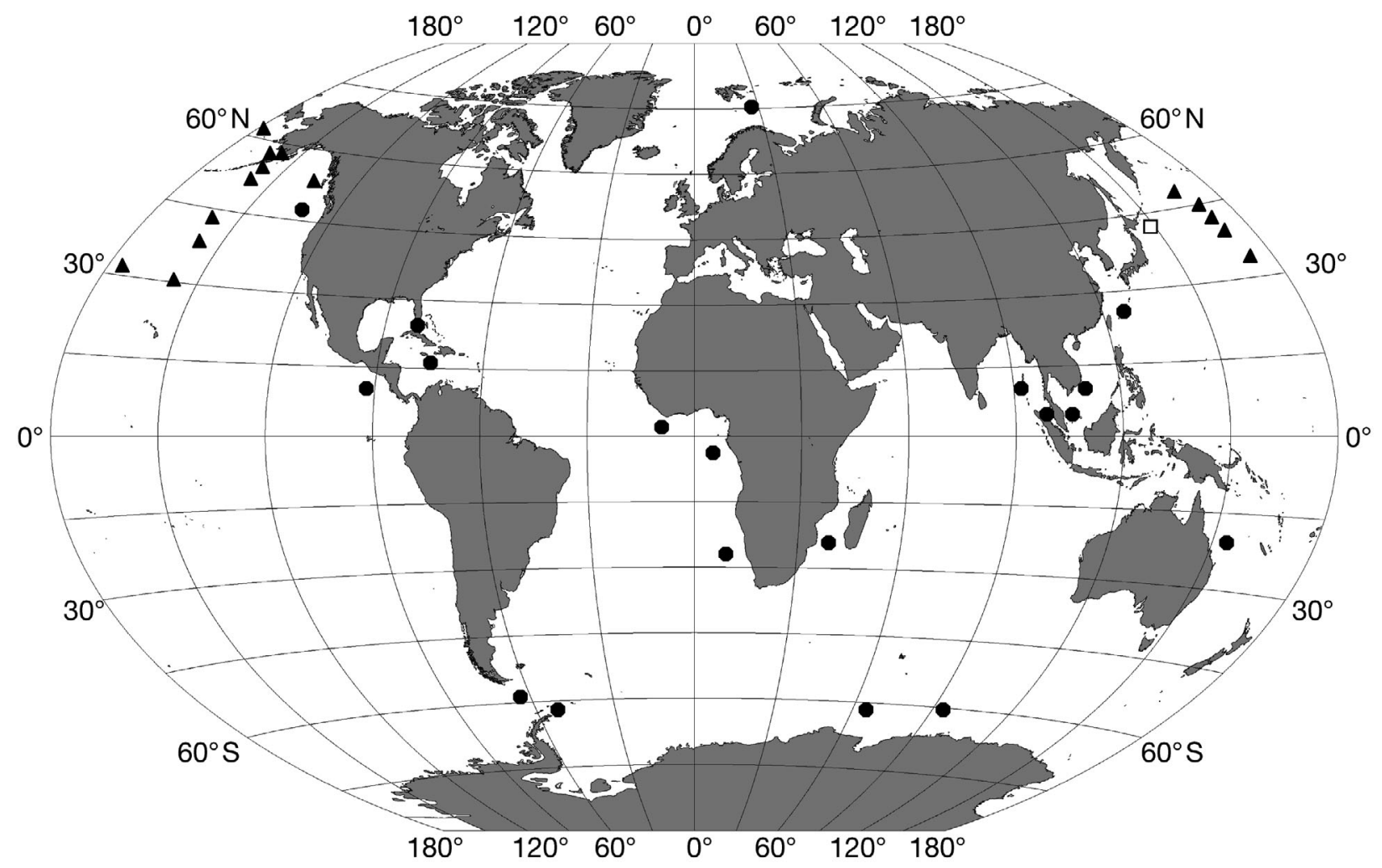

Fig. 1. Geographical distribution of study sites of copepod respiration, including those for epipelagic species (•: Ikeda et al. 2001; $\Delta$ : F. Sano \& T. Ikeda unpubl. data) and mesopelagic through bathypelagic (Ikeda et al. 2006) and abyssopelagic species (Ikeda unpubl.) in the western North Pacific Ocean ( $\square$ )

2001, 2004, F. Sano \& T. Ikeda unpubl. data). In these epipelagic datasets, the temperatures of the water where the copepods were collected ranged from seawater near the point of freezing $\left(-1.7^{\circ} \mathrm{C}\right)$ in the polar seas to tropically warm water $\left(28.5^{\circ} \mathrm{C}\right)$. The 188 deepsea respiration datasets were from the mesopelagic (500 to $1000 \mathrm{~m}$ ), upper-bathypelagic (1000 to $2000 \mathrm{~m}$ ) and lower-bathypelagic (2000 to $3000 \mathrm{~m}$ ) (Ikeda et al. 2006a) supplemented by the abyssopelagic (3000 to $5000 \mathrm{~m}$ ) zones (T. Ikeda unpubl.), all in the western North Pacific Ocean (Fig. 1). Respiration rates of copepods from these bathymetric zones were determined at the mean temperatures of each zone $\left(1.5\right.$ to $\left.3^{\circ} \mathrm{C}\right)$ and at near ambient oxygen concentrations (see below) by using fresh seawater from the mid-sampling depth of each zone collected just prior to the experiment (for details of the procedures, see Ikeda et al. 2006a). No decompression effect was taken into account for the experiment on deep-sea copepods, since a lack of appreciable hydrostatic pressure effects on the respiration rates has been confirmed experimentally on bathypelagic copepods and other zooplankton (cf. Ikeda et al. 2001, 2006a). The validity of respiration data on copepods from the mesopelagic or from deeper zones was confirmed by the enzyme activities of the electron transfer system (ETS) of copepods from the same zone, i.e. the ratios of ETS to respiration were close to the theoretical value of 2 (Ikeda et al. 2006a). A total of 253 datasets representing 21 families, 51 genera and 108 species of marine pelagic copepods was used in our analysis (see Appendix 1 at: www.intres.com/articles/suppl/m339p215_app.pdf). In terms of dried body mass (DM), the smallest copepod was Paracalanus parvus $(0.0038 \mathrm{mg})$ and the largest was Bathycalanus bradyi (34.5 mg).

In addition to the 2 conventional independent variables ( $x_{1}$ : body mass; and $x_{2}$ : habitat temperature) used in the global respiration model for marine epipelagic copepods (Ivleva 1980, Ikeda et al. 2001), 2 new independent variables $\left(x_{3}\right.$ : oxygen saturation; and $x_{4}$ : depth of occurrence) were introduced to the global-bathymetric model of the present study (Table 1). $x_{3}$ was expressed as a fraction of saturation (full saturation = 1.00), and respective saturation values for epipelagic, mesopelagic, upper-bathypelagic, lower-bathypelagic and abyssopelagic zones were 1.00, 0.13, 0.20, 0.32 and 0.45 (the last 4 values are the means of respective strata based on our own measurements in the western subarctic Pacific, cf. Fig. 1). $x_{4}$ was expressed as middepth of each sampling stratum, e.g. $750 \mathrm{~m}$ for the 
Table 1. Stepwise (forward selection) multiple regression analyses of respiration rates $\left(y: \mu l \mathrm{O}_{2}\right.$ ind..$\left.^{-1} \mathrm{~h}^{-1}\right)$ on body mass $\left(x_{1}: \mathrm{mg}\right.$ ind.$\left.^{-1}\right)$, habitat temperature $\left(x_{2}: \mathrm{K}\right.$ for theoretical model, ${ }^{\circ} \mathrm{C}$ for empirical model), oxygen saturation ( $x_{3}: 1.00$ for full saturation) and habitat depth $\left(x_{4}: \mathrm{m}\right)$ for marine planktonic copepods $(\mathrm{N}=253)$. Theoretical regression equation: $\ln \left(y / x_{1}{ }^{0.75}\right)=a_{0}+a_{2}\left(1000 x_{2}{ }^{-1}\right)$ $+a_{3} x_{3}+a_{4} \ln x_{4} ;$ empirical regression equation: $\ln y=a_{0}+a_{1} \ln x_{1}+a_{2} x_{2}+a_{3} x_{3}+a_{4} \ln x_{4}$. DM: dry mass; NM: nitrogen; CM: carbon; $\mathrm{R}^{2}$ : correlation coefficient

\begin{tabular}{|c|c|c|c|c|c|c|c|c|}
\hline \multirow{2}{*}{$\begin{array}{l}\text { Regression } \\
\text { model }\end{array}$} & \multirow{2}{*}{$\begin{array}{c}\text { Body mass } \\
\text { unit }\end{array}$} & \multirow[t]{2}{*}{ Step } & \multicolumn{6}{|c|}{ - Equation coefficients } \\
\hline & & & $a_{0}$ & $a_{1}$ & $a_{2}$ & $a_{3}$ & $a_{4}$ & $\mathrm{R}^{2}$ \\
\hline \multirow[t]{9}{*}{ Theoretical } & DM & 1 & 30.874 & & -8.800 & & & 0.668 \\
\hline & & 2 & 19.348 & & -5.355 & & -0.146 & 0.746 \\
\hline & & 3 & 18.305 & & -5.227 & 0.537 & -0.089 & 0.760 \\
\hline & NM & 1 & 29.710 & & -7.966 & & & 0.675 \\
\hline & & 2 & 21.350 & & -5.746 & 0.813 & & 0.750 \\
\hline & & 3 & 18.887 & & -4.907 & 0.512 & -0.070 & 0.762 \\
\hline & $\mathrm{CM}$ & 1 & 33.499 & & -9.385 & & & 0.669 \\
\hline & & 2 & 21.364 & & -5.758 & & -0.155 & 0.746 \\
\hline & & 3 & 20.230 & & -5.619 & 0.584 & -0.092 & 0.761 \\
\hline \multirow[t]{12}{*}{ Empirical } & DM & 1 & -0.894 & 0.367 & & & & 0.364 \\
\hline & & 2 & -1.289 & 0.649 & 0.094 & & & 0.669 \\
\hline & & 3 & -0.258 & 0.737 & 0.064 & & -0.145 & 0.737 \\
\hline & & 4 & -0.815 & 0.750 & 0.064 & 0.539 & -0.091 & 0.752 \\
\hline & NM & 1 & 0.146 & 0.421 & & & & 0.420 \\
\hline & & 2 & 0.456 & 0.705 & 0.092 & & & 0.729 \\
\hline & & 3 & 0.359 & 0.777 & 0.072 & 0.855 & & 0.791 \\
\hline & & 4 & 1.073 & 0.796 & 0.063 & 0.543 & -0.079 & 0.803 \\
\hline & $\mathrm{CM}$ & 1 & -0.667 & 0.337 & & & & 0.344 \\
\hline & & 2 & -0.878 & 0.606 & 0.094 & & & 0.644 \\
\hline & & 3 & -1.116 & 0.678 & 0.075 & 0.878 & & 0.708 \\
\hline & & 4 & -0.392 & 0.700 & 0.065 & 0.549 & -0.085 & 0.722 \\
\hline
\end{tabular}

sampling from the mesopelagic zone (500 to $1000 \mathrm{~m})$, $1500 \mathrm{~m}$ from the upper-bathypelagic zone (1000 to $2000 \mathrm{~m}$ ) and so on. $x_{1}$ was expressed as DM, nitrogen (NM) or carbon (CM) since the choice of the body mass unit is known to cause somewhat different results (Ivleva 1980, Ikeda et al. 2001). Two regression models were adopted as a basis to build a global-bathymetry model for respiration in pelagic copepods; one was a theoretical model characterized by the scaling exponent of $3 / 4$ (or 0.75 ) and the Arrhenius relationship for the temperature effect $\left(R=R_{0} M^{3 / 4} \mathrm{e}^{-E / k T}\right.$, where $R$ is respiration rate, $M$ is body mass, $T$ is absolute temperature, $E$ is an average activation energy for the ratelimiting enzyme-catalyzed biochemical reactions of metabolism, $k$ is Boltzmann's constant and $R_{\mathrm{o}}$ is a normalization constant, cf. Gillooly et al. 2001) and the other was empirical model characterized by undefined scaling exponent and the Van't Hoff rule $\left(Q_{10}\right)$ for the temperature effect (Ikeda et al. 2001) (Table 1).

It is noted that a number of criticisms of the theoretical model above have been expressed. One of 2 components of the model, the scaling exponent 3/4 (or 0.75) has been questioned from the viewpoint of its theoretical justification and verification by the data (Dodds et al. 2001). The other component, the Arrhenius relationship, implies that there is an automatic increase in respiration rate with increasing temperature, with no provision for laboratory acclimation, seasonal acclimation or evolutionary adaptation known for respiration-temperature relationships for marine animals (Clarke \& Fraser 2004).

\section{RESULTS}

Preliminary analysis was made to determine the coefficient $a_{2}\left(=-E k^{-1}\right)$ of temperature $x_{2}$ of the theoretical model first, by plotting the epipelagic respiration rate standardized to the rate $\left(R_{0}\right)$ of specimens weighing $1 \mathrm{mg} \mathrm{DM}\left(R_{\mathrm{o}}=R \mathrm{DM}^{-0.75}\right)$ against inverse temperature $(1000 / \mathrm{K})$ (Fig. 2A). The resultant slope $(-5.406)$ for epipelagic copepods was used to compute respiration rate at a given temperature (designated as $10^{\circ} \mathrm{C}$ ) of both epipelagic and mesopelagic-abyssopelagic copepods, which was plotted against copepod DM (Fig. 2B). In both figures, it is clear that the mesopelagic-abyssopelagic rate values only partially overlap the epipelagic values, and the former distribute well below the latter at equivalent inverse temperature and body mass. The standardized respiration rates $\left(R_{\mathrm{o}}\right)$ at $10^{\circ} \mathrm{C}$ of epipelagic, mesopelagic, upperbathypelagic, lower-bathypelagic and abyssopelagic 

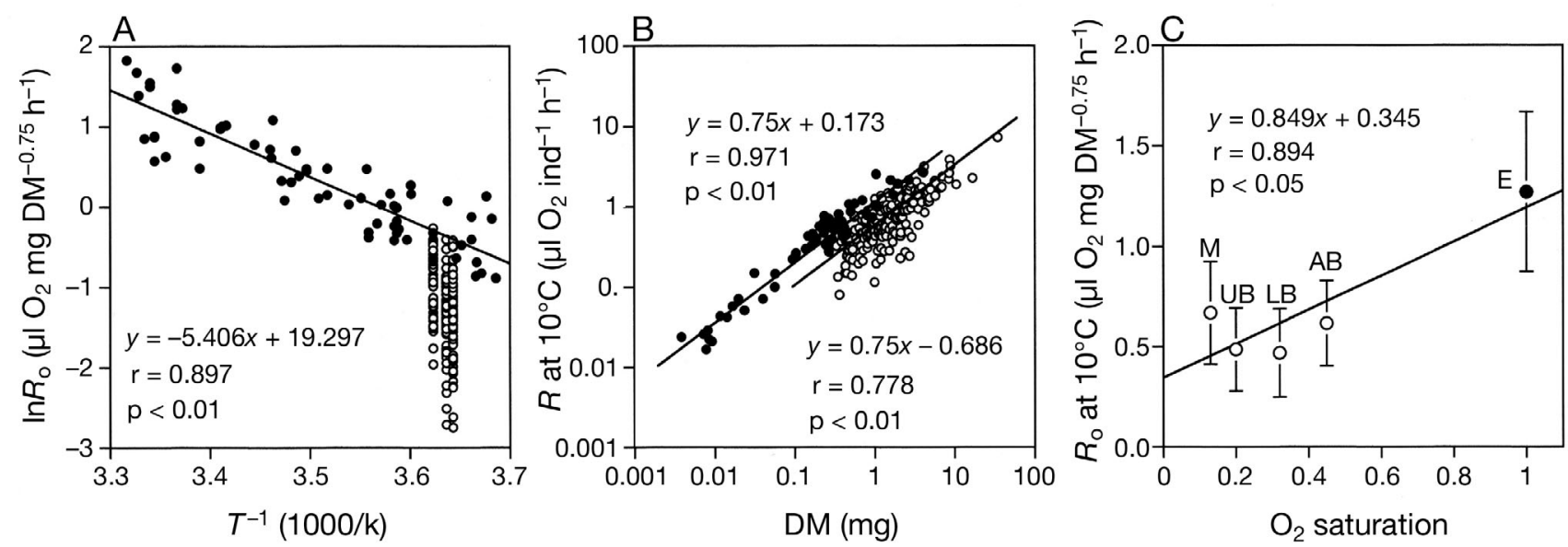

Fig. 2. Copepod respiration rates and variables. (A) Relationship between the respiration rate of copepods standardized to a body size of $1 \mathrm{mg}$ dry mass $(\mathrm{DM}),\left(R_{\mathrm{o}}\right)$ and inverse temperature $\left(T^{-1}\right)$; fitted least square regression line only for epipelagic copepod data. (B) Relationship between respiration rate standardized to the rate $(R)$ at $10^{\circ} \mathrm{C}$ and $\mathrm{DM}$, and fitted regression lines with preset slope (0.75) for epipelagic and mesopelagic-abyssopelagic copepod data. (C) Relationship between respiration rates standardized to a body size of $1 \mathrm{mg} \mathrm{DM}\left(R_{\mathrm{o}}\right)$ and at $10^{\circ} \mathrm{C}$ and oxygen concentration $\left(\mathrm{O}_{2}\right.$ saturation), and fitted least square regression line. -: epipelagic copepods; O: mesopelagic through abyssopelagic copepods. Bathymetric abbreviations: $\mathrm{E}=$ epipelagic, $\mathrm{M}=$ mesopelagic, $\mathrm{UB}=$ upper-bathypelagic, $\mathrm{LB}=$ lower-bathypelagic, $\mathrm{AB}=$ abyssopelagic

copepods were plotted against oxygen saturations of respective bathymetric zones (Fig. $2 \mathrm{C}$ ). While the respiration data were rather biased to lower oxygen saturation, there was a significant positive correlation $(\mathrm{p}<$ $0.05)$ between the two.

After confirming significant effects of 3 out of the 4 individual variables on the respiration rates (Fig. 2), the attributes of these 4 variables were analyzed simultaneously by using stepwise multiple regression (forward selection) method (Sokal \& Rohlf 1995). Independent variables were added if $p<0.05$ and removed if $\mathrm{p}>0.10$. The calculation was conducted using SYSTAT version 10.2. The results show that the 4 independent variables were all significant although the priority of addition oxygen saturation $\left(x_{3}\right)$ or depth of occurrence $\left(x_{4}\right)$ differed depending on the choice of the body mass unit in both models (Table 1). The choice of body mass unit also affected the correlation coefficients derived from the empirical model $\left(R^{2}=0.72\right.$ to 0.80 for the regression equations at Step 4, Table 1), but this was not the case in the theoretical model $\left(R^{2}=0.76\right.$ for those at Step 3).

\section{DISCUSSION}

Our results indicate clearly that not only body mass and temperature but also the depth of occurrence and ambient oxygen saturation contributed significantly to the variance of the copepod respiration data from the epipelagic through the abyssepelagic zones (Table 1). When compared with the equivalent body mass unit, there was little difference in the partial regression coefficients of each variable (excepting those of the temperature, the effect of which was expressed as different mathematical forms in each model) and the correlation coefficients between the theoretical and empirical models. While the best fit regression equation was that of the empirical model in which body mass was expressed by the nitrogen unit $\left(R^{2}=0.80\right.$, cf. Table 1), the differences from the rest of the 5 full regression equations $\left(R^{2}=0.72\right.$ to 0.76$)$ were not marked.

The positive effect of oxygen concentration $\left(x_{3}\right)$ was not considered in the previous global respiration model of marine pelagic copepods because the epipelagic environments of the world's oceans are oxygen saturated throughout. Nevertheless, a significant effect of oxygen saturation on respiration in copepods is to be expected since copepods lack respiratory organs such as gills and their respiration is determined by the gradient of oxygen concentration through body integuments (Wolvekamp \& Waterman 1960). Respiration rates of micronektonic crustaceans living in the oxygen-poor mesopelagic zone off South California, USA, have been reported to be one-half those of oxygen-rich mesopelagic zones of Antarctic waters (Ikeda 1988). Some pelagic crustaceans with respiratory organs (gills) which live in or in close proximity to the minimum oxygen zone are able to respire at low oxygen concentrations (Childress \& Seibel 1998).

The negative effect of the depth of occurrence $\left(x_{4}\right)$ on the respiration of marine pelagic copepods in the 
present analysis supports the 'predation-mediated selection' hypothesis (Ikeda et al. 2006a). According to this hypothesis, the lower levels of respiration in deeper-living copepods is a result of low selective pressure for high activity in copepods in the deep-sea. Pelagic life is characterized by the lack of shelters. Copepods living in the illuminated epipelagic zone have the advantage of a rich food supply, but also need to be active enough to avoid predation risk. A recent observation of a progressive decline in the nitrogen (= muscle) concentration in copepods living in the epipelagic through the abyssopelagic zones supports the hypothesis (Ikeda et al. 2006b). It is noted that the 'visual-interactions' hypothesis (Childress 1995) which has been proposed to explain the reduced respiration rates of deeper-living micronektonic fishes, crustaceans and cephalopods with well-developed visual perception systems (eyes) does not apply to pelagic animals without visual perception systems such as copepods, but it predicts the lack of depth-related changes in the respiration rates of pelagic copepods. The lower respiration rates of mesopelagic through abyssopelagic copepods found here supports the predictions of that hypothesis.

Compared with the previous global respiration model (Ikeda et al. 2001), the global-bathymetric respiration model (Table 1) described in the present study is an advanced version, which provides a solid basis for assessing energy flux and biogeochemical cycles of carbon via copepod communities in the marine pelagic realm at larger spatial scales. Taking into account the 4 independent variables $\left(x_{1}, x_{2}, x_{3}\right.$ and $\left.x_{4}\right)$, the present global-bathymetric model explained 72 to $80 \%$ of the variance in the epipelagic through abyssopelagic respiration data. The amount of explained variance by the 4 variables in the globalbathymetric model is less than that (93 to $96 \%$ ) of the global model, which has only 2 variables (Ikeda et al. 2001). This may be partially due to the low precision of the respiration data for copepods from the mesopelagic through the abyssopelagic zones, since most of the mesopelagic data were based on measurements using single specimens (Ikeda et al. 2006a). This reflects the extremely low abundance of most deep-sea copepods as compared with shallow-living copepods. In the future, the global-bathymetric model can be improved by the addition of new respiration datasets of copepods from other extreme deep-sea environments characterized by a high temperature and/or high oxygen saturation (the present data are of low temperature and low oxygen in the western subarctic Pacific); possible candidates for such study sites are the Arabian Sea, the Sulu Sea and the entire North Atlantic Ocean.
Acknowledgements. We thank A. Clarke and 4 anonymous referees for comments which improved the manuscript. This study was supported partly by grant JSPS KAKENSHI 1920900 to T.I.

\section{LITERATURE CITED}

Aristegui J, Agusti S, Middleburg JJ, Duarte CM (2005) Zooplankton respiration. In: del Geiorgio PA, Williams PJleB (eds) Respiration in aquatic ecosystems. Oxford University Press, Oxford, p 181-205

Buitenhuis E, Quere CL, Aumont Q, Beaugrand G and 6 others (2006) Biogeochemical fluxes through mesozooplankton. Global Biogeochem Cycles 20:GB2003, doi:10.1029/2005GB002511

Childress JJ (1995) Are there physiological and biochemical adaptations of metabolism in deep-sea animals? Trends Ecol Evol 10:30-36

Childress JJ, Seibel BA (1998) Life at stable low oxygen levels: adaptations of animals to oceanic oxygen minimum layers. J Exp Biol 201:1223-1232

Clarke A, Fraser KPP (2004) Why does metabolism scale with temperature? Funct Ecol 18:243-251

Dodds PS, Rothman DH, Weitz JS (2001) Re-examination of the '3/4-law' of metabolism. J Theor Biol 209:9-27

Gillooly JF, Brown JH, West GB, Savage VM, Charnov EL (2001) Effects of size and temperature on metabolic rate. Science 293:2248-2251

Hernandez-Leon S, Ikeda T (2005) A global assessment of mesozooplankton respiration in the ocean. J Plankton Res $27: 153-158$

Ikeda T (1988) Metabolism and chemical composition of crustaceans from the Antarctic mesopelagic zone. Deep-Sea Res 35:1991-2002

Ikeda T, Torres JJ, Hernandez-Leon S, Geiger SP (2000) Metabolism. In Harris RP, Wiebe PH, Lenz J, Skjoldal HR, Huntley M (eds) ICES zooplankton methodology manual. Academic Press, San Diego, CA, p 455-532

Ikeda T, Kanno Y, Ozaki K, Shinada A (2001) Metabolic rates of epipelagic marine copepods as a function of body mass and temperature. Mar Biol 139:587-596

Ikeda T, Sano F, Yamaguchi A (2004) Metabolism and body composition of a copepod (Neocalanus cristatus: Crustacea) from the bathypelagic zone of the Oyashio region, western subarctic Pacific. Mar Biol 145:1181-1190

Ikeda T, Sano F, Yamaguchi A, Matsuishi T (2006a) Metabolism of mesopelagic and bathypelagic copepods in the western North Pacific Ocean. Mar Ecol Prog Ser 322:199-211

Ikeda T, Yamaguchi A, Matsuishi T (2006b) Chemical composition and energy content of deep-sea calanoid copepods in the western North Pacific Ocean. Deep-Sea Res I 53: 1791-1809

Ivleva IV (1980) The dependence of crustacean respiration rate on body mass and habitat temperature. Int Rev Ges Hydrobiol 65:1-47

Longhurst AR (1985) The structure and evolution of plankton communities. Prog Oceanogr 15:1-35

Mauchline J (1998) The biology of calanoid copepods. Adv Mar Biol 33:1-710

Sokal RR, Rohlf FJ (1995) Biometry. The principles and practice of statistics in biological research. Freeman, New York

Wolvekamp HP, Waterman TH (1960) Respiration. In: Waterman TH (ed) The physiology of Crustacea. Academic Press, New York, p 35-100

Submitted: September 25, 2006; Accepted: December 6, 2006 Proofs received from author(s): May 24, 2007 